\title{
The influence of information technology (IT) on organization leadership and performance
}

\author{
Nadia Saleh Mahdi \\ Department of Hotel Management - College of Tourism Sciences - University of Karbala - Iraq
}

\begin{abstract}
Leadership of modern organizations depend upon ever greater levels of information technology (IT) now, such as big data and management $\&$ data analytics, a trend which shows no sign of abating now. However, not all modern organizations have benefited from such IT investments, resulting in mixed perceptions on the value of IT. Organizations must be knowledgeable in order to properly utilize IT tools and be able to apply that knowledge to create unique competencies in order to gain sustained advantage from IT investments. Information technology in the modern organizations has been proposed as the mechanism to accomplish the leadership in the concerned industries. Existing empirical research demonstrates that IT may indeed act as a mediator for the effect of leadership on modern organizational outcomes. Yet, this study is not consistent in the conceptualizations of the relationships involved, nor in their definitions and measurement of IT investment spending. Thus, they chase numerous creative and innovative procedures and approaches while adding a substantial role of informational technology in the administration of such practice. This study aims to address these concerns in an organization setting by using structural equation modelling (SEM) to compare the effectiveness of descriptive and normative measures of IT as mediating variables in knowledge-intensive organizations. Implications for research and practice are discussed.
\end{abstract}

\begin{tabular}{ll}
\hline Keywords: & $\begin{array}{l}\text { Information technology (IT), leadership, modern organizations, information system, } \\
\text { organization leadership. }\end{array}$ \\
\hline
\end{tabular}

Corresponding Author: Nadia Saleh Mahdi

Departement: Department of Hotel Management

University: University of Karbala

Address: Karbala, Iraq.

E-mail: nadia.s@uokerbala.edu.iq

\section{Introduction}

Organizations of all kinds are relying more on data and information processing systems than ever before. Investments in the tools of information technology (IT) infrastructures have been assumed to provide enhanced decision-making capabilities, increased efficiency, and improved productivity, and finally the leadership role in the organizations from the concerned industries [1]. A prime example for modern organizations, though not the only example, is that of 'big data' and 'analytics' These relatively new technologies have high expectations to enhance organizational outcomes for the leadership and, consequently, are invested in heavily. Business organizations are looking for and need technology solutions that can deliver timely and information based on a single view of the operational data, rather than multiple views and resultant inconsistent information for organization management.

While big data or organizational analytics technology may be a relevant modern example of technology for enhancing organizational performance, the issues encountered with their use in practice are not limited to these technologies [2]. More generally, there are examples where 
technologies lead to more organizational problems such as 'analysis paralysis' whereby managers spend too much time and effort analyzing an issue before action is taken which may prevent a timely response to that issue. There are also examples of organizations which spend an inordinate amount of resources collecting, organizing, and storing information that is never used to inform decision making, resources that can arguably be better used elsewhere with a higher return on investment thus gives the edge-cutting response to the leadership of that organization. "The imprudent integration of such IT systems may eventually lead to a less desirable competitive position within an industry". IT can become as much an impediment as an enabler of organizational performance and leader roles in other concerned organizations [2,3]. These issues represent a salient challenge for modern organizations which are increasingly reliant on large scale IT systems for organizational leadership and performance.

The challenges of IT utilization will only become more important as organizations are expected to increase their reliance on and utilization of organizational data processing systems. While automated forms of data analysis, such as statistical analyses, are good low-level tools, they are often inadequate for managers to 'get the big picture'. The development of this broad understanding is required to make informed organizational decisions and leadership at the highest level. Low-level analysis does not always provide this insight where more human perspectives are needed to answer the question 'what does this mean?' However, human analysis becomes problematic when datasets are very large, such as with big data. Big data databases can easily become so large that it would take human analysts too long to interpret manually. These situations then require a combination of automated analysis and human insight which is a combination that is often difficult to develop in practice [3]. For some organizations, this has already happened; for others, it may just be a matter of time. Such prognostication suggests that the issue of how to best utilize IT will go beyond the initial investments in technological infrastructure, beyond a simple enhancement of existing business processes, and will require entirely new ways of operating. Modern technology contributes to the strategic elasticity \& efficiency in organizations and also to the capability for the production of products, high quality services, various market's low cost, escalating the customer response speed and reduction of the boarders, thus these things would definitely help out manager in achieving the goal and consequently become adopt a leadership role in the organizations [3].

\subsection{The aim of this study is limited to the following points}

1- The significance of the relationship between IT and organizational leadership through the theoretical framework and is mediated by organizational learning.

2- Describing the utmost significant and theoretical perspective of Modern Organization of information technology for human resource development and management.

3- The mandatory alterations needed by institutes' organizational structures and the impact of information technology on modern organizations.

4- Finding the empirical studies on Information Technology in a Competitive organization setting for organizational leadership.

5. How we can measure the Information technology competence through different models for the leadership of the organization.

6. The benefits of having information technology in a normal organization.

Before addressing these points to start identifying a perception of leadership, it is vital to understand the great significance attained by pioneers in modern business organizational field due to chief engine for economic actions and being industrial growth leaders.

\section{Leadership through Information Technology perspective}

Research into the modern organizations use of IT observes that IT infrastructure itself is not sufficient for competitive advantage as infrastructure is too easily imitated by other organizations 
and an inability to properly utilize existing resources. Instead, existing research demonstrates that, when combined with organizational leadership [4]. IT may be used to develop unique organizational capabilities which then enable enhanced organizational performance; organizations must know how, and be willing to use, these tools properly in the form of IT capabilities.

The leadership of the auspicious and significant fields is deliberated as identical for the advanced industrial and developing countries economy. Because it assists the dynamic involvement of the entrepreneurship in general economic progress of all countries. As the idea of "leadership" has become crucial for the modern economy, thus, the word Entrepreneur's Arabic meaning had been changed three time in latest decades. Examples of specific technologies employed in organizations mainly include areas such as communication technology, knowledge repositories, databases, and analytical and computational capabilities which will consequently increase the leadership role for any organization to pursue [4]. Organizations prefer several kinds of technology for the conversion of inputs to outputs. There is a resilient relation among the structures utilized in the organization and the production processes size. It was also observed that the competence and efficacy of the organization mainly depends on the proportionality's amount amongst the organizational structure and technology.

\section{Theoretical perspective of Modern Organization}

Areas that have not traditionally used IT have also started to embrace its use in the business organizations. Modern organizations are using technology in areas for examples include human resource management (HRM), customer relations management (CRM), enterprise resource planning (ERP) [9], and social media integration. It is not only the quantity of informational products that is growing but also the variety of information itself as together, these tools cover a vast swath of different data types and ranges of information for the management and leadership role for any organization. Data repositories, in general, have become central to many existing modern organization processes that rely on data transactions, reports, and analyses. Modern incarnations of data repositories often fall under the purview of knowledge management approaches. For example, tools that aid in information storage, organization, retrieval, and sharing are often characterized as 'big data' databases which are able to store very large quantities and varieties of data with high velocities of data transfer.

Organizational studies, on the other hand, contend that technology [6] should be thought of from a broader, less concrete perspective. Seeing the organizations from the social constructivist view, allows us to see how technologies reflect human agency and so embody the choices of the organization. The author suggests that technologies can then be shifted by the user as they become integrated into the modern organization and their application directed to create the desired leadership outcome.

\section{The impact of information technology on modern organizations}

First, IT is able to better leverage existing resources to expand the potential choices and breadth of action than would otherwise be possible. Second, the organization's choice of which technologies to employ and how to employ them serves to reinforce the shared values of the organization as organizations must make choices based on the shared goals and priorities that result in artefacts which stand as examples of their shared vision. Management information systems (MIS) [10], for example, have developed from a more technological perspective towards integrating more of the social context of people using technology. Information technology should then be thought of as both social and physical as technology both impacts the potential choices of organizations as well as embodies the current choices made by organizations.

This implies that technology cannot be considered separately from the way that people behave within the organization, supporting the development in the MIS literature to investigate not just technology but also its use in practice. Technology and behavior must then also interact over time as technology 
influences the behavior of organizations and behavior influences organizational leadership. Faced with new opportunities, afforded by enhanced technological capability, organizations must decide which paths to follow and in doing so embody the values and priorities of that organization in their future choices. Accordingly, organizational values influence technological investment [7] which in turn influences future choices that must be made on the basis of their organizational values. This process has large implications for the organization over time because this process propagates iteratively into the future allowing small scale changes to compound over time leading to large scale influences as the organization is forced to continually come up with new answers to questions such as 'what can we do' versus 'what should we do?'. Moreover, the usage of advanced technology is a distinct indication for all industrial sectors and facilitated modern technology for coordination among all resources \& procedures. It also attains the access of business to the finest facility, products for customers, more elasticity to reach customers, achieving a greater value for business and complete coverage of markets. Because of the extreme competition, the globalization turns out to be the impacting the development and expansion of the global economy while opening the local market. Moreover, the global trends of technology [7] have upsurged the indecision and hazards of entrepreneurial organization as forecast markets. However, the increased fluctuations and string competition have improved the complexity of prediction about growth attainment.

\section{Information Technology in a Competitive organization setting for organizational leadership}

It is often suggested that IT has become so ubiquitous an investment that it is assumed to provide value, increase productivity, and competitiveness as a matter of course. However, investments in IT have not always resulted in the expected gains. An example comes in the form of big data. Here, it is argued that vast volumes of data are difficult for people to interpret and make sense of at these grand scales which may impede effective understanding and use of such information resulting in cherrypicking of data, and inability to identify patterns and make appropriate generalizations [8]. Failure to properly comprehend the data being relied upon to make organizational decisions may distort intentions and leadership role of organization, discourage the use of technological aids, or worse, set the scene for poor organizational decision making based on misunderstanding and misplaced confidence in the leadership processes, thus it effects the organizational setting. The simple existence of an information technology infrastructure is not sufficient for enhanced organizational processes as the potential for improper use of technology may undermine competitive positions. Technologies, such as big data, then need additional context to provide a competitive advantage whereas Knowledge is necessary but not sufficient for competitive use of IT resources. Unique organizational knowledge is what enables the organization to fully utilize IT resources and it is what endows IT with all the properties of a competitive advantage $[2,8]$.

The globalization and revolution of technology are the functional keys for the recent rivalry, furthermore, operating the modern technology is increasing as it upsurges the capacity of its resources and decreases the cost [9]. Thus, technologies have turned to be the key indicators for the leadership strategies and for seizing the market opportunities.

\section{Two models for organizational leadership}

Organizational leadership will be measured in two flavors:

\section{Descriptive Leadership}

2. Normative Leadership

First load onto a series of latent variables that represent the processes of leadership in organizations which themselves load onto a second order latent variable that reflects overall leadership in the organization. Descriptive leadership measures include information acquisition, information dissemination, information interpretation, and organizational memory. Normative leadership measures include clarity of purpose and mission, shared interpretation, experimentation, transfer of knowledge, and team and group problem solving. 


\section{Information technology (IT) competency model for leadership in modern organizations}

The model that will be used as a starting point for this study as it is the most relevant and utilizes three main variables: IT competency [12], organizational learning, and organizational performance. This model will form the basis for this study by first replicating its findings, and second, by building upon this model with a new measurement of leadership. The models will first test the direct relationship between IT and performance as well as mediating models with organization leadership between IT and performance. The study break IT competency down into measures of IT knowledge, IT operations, and IT objects which reflects not only the physical tools of IT but also how to use them and their application to the business problems at hand. This combination of a measure of physical IT assets as well as its use in practice aligns with perspectives from the literature search that highlight the importance of these two aspects of technology in this setting.

Organizational leadership will be measured using high level survey questions that seek people's perceptions of organizational leadership [11]. This is due to the wide variety of organizational types that could be included in knowledge intensive industries which may not all define success in a similar manner. As such, leadership will be measured as perceptions of organizational success at an:

- Individual level

- Group level

- Organizational level

which together will load onto a latent variable that represents all levels of leadership.

There are three models [12] that will be used in this study: the direct effects model that will form the basis of comparison for all other models, the mediation model with descriptive measures of organizational leadership, and the mediation model with normative measures of organizational leadership. These models are interconnected in a way to experiment the categories that make up IT competency, organization leadership, and organizational performance.

- The direct effects model of IT competency

Describes the direct effects model which was created consisting of only two main variables, level of IT competency and organizational leadership (in addition to the control variables) [12].

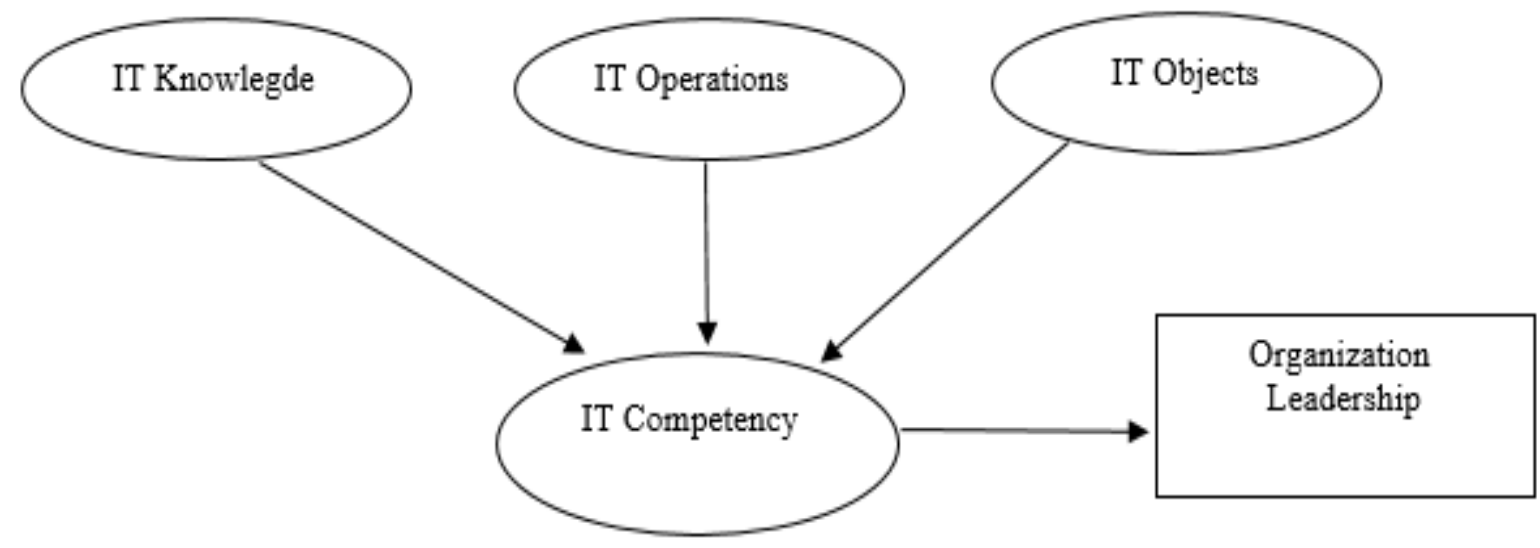

Figure 1. This explains the IT competency in any organization by the direct effect method [12]

- The mediation model with descriptive measures of organizational leadership of IT competency

Next, created descriptive mediation model to test different variations of organizational leadership on IT competency and results. The first mediation model in Figure 2 uses the descriptive measure of organizational leadership as the mediating variable. 


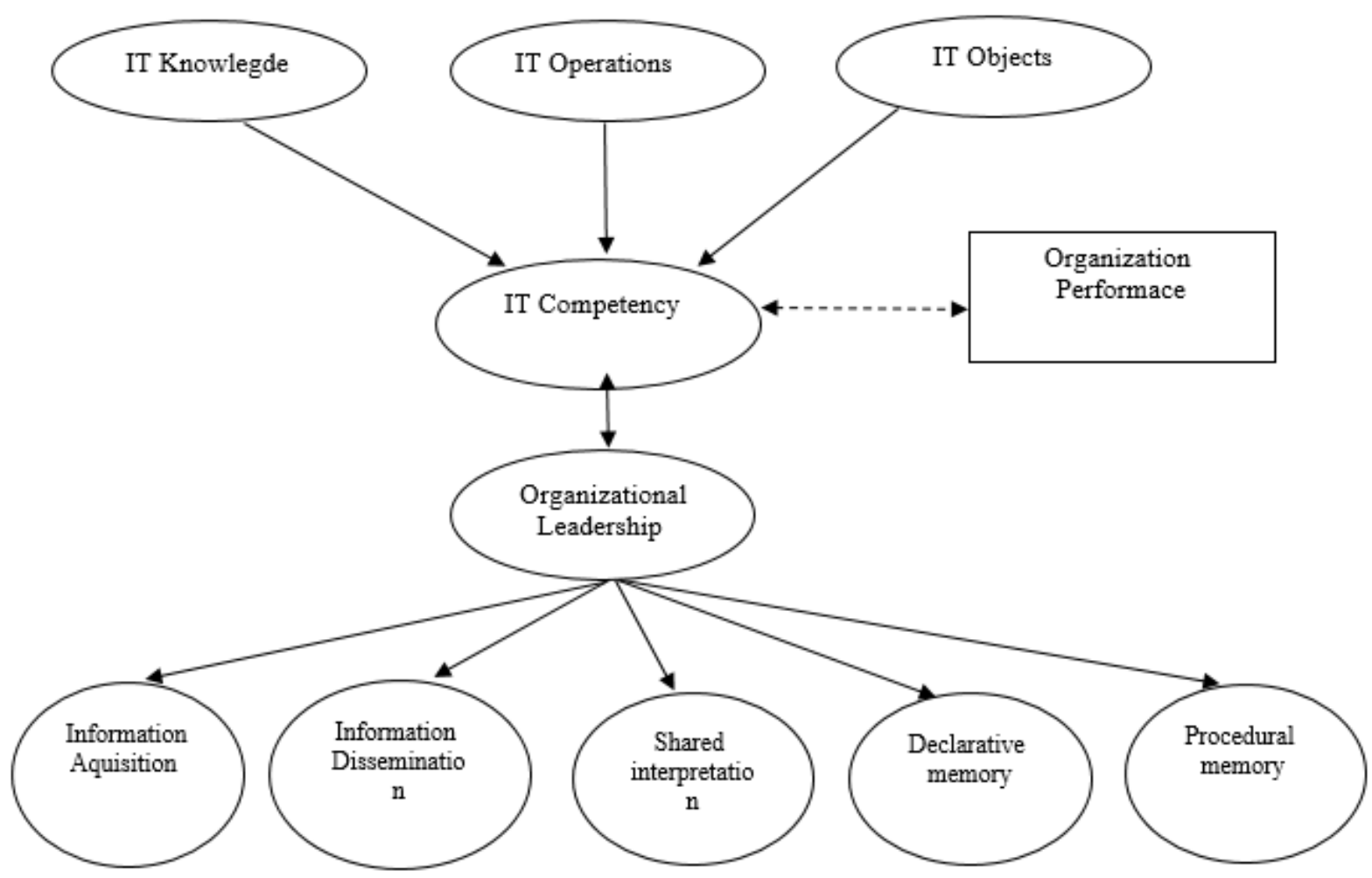

Figure 2. This explains the descriptive IT competency model in the organization for achieving the leadership role in the industries [12]

\section{- The mediation model with normative measures of organizational leadership of IT competency}

The second mediation model in Figure 3 uses the normative measure of organizational leadership as the mediating variable.

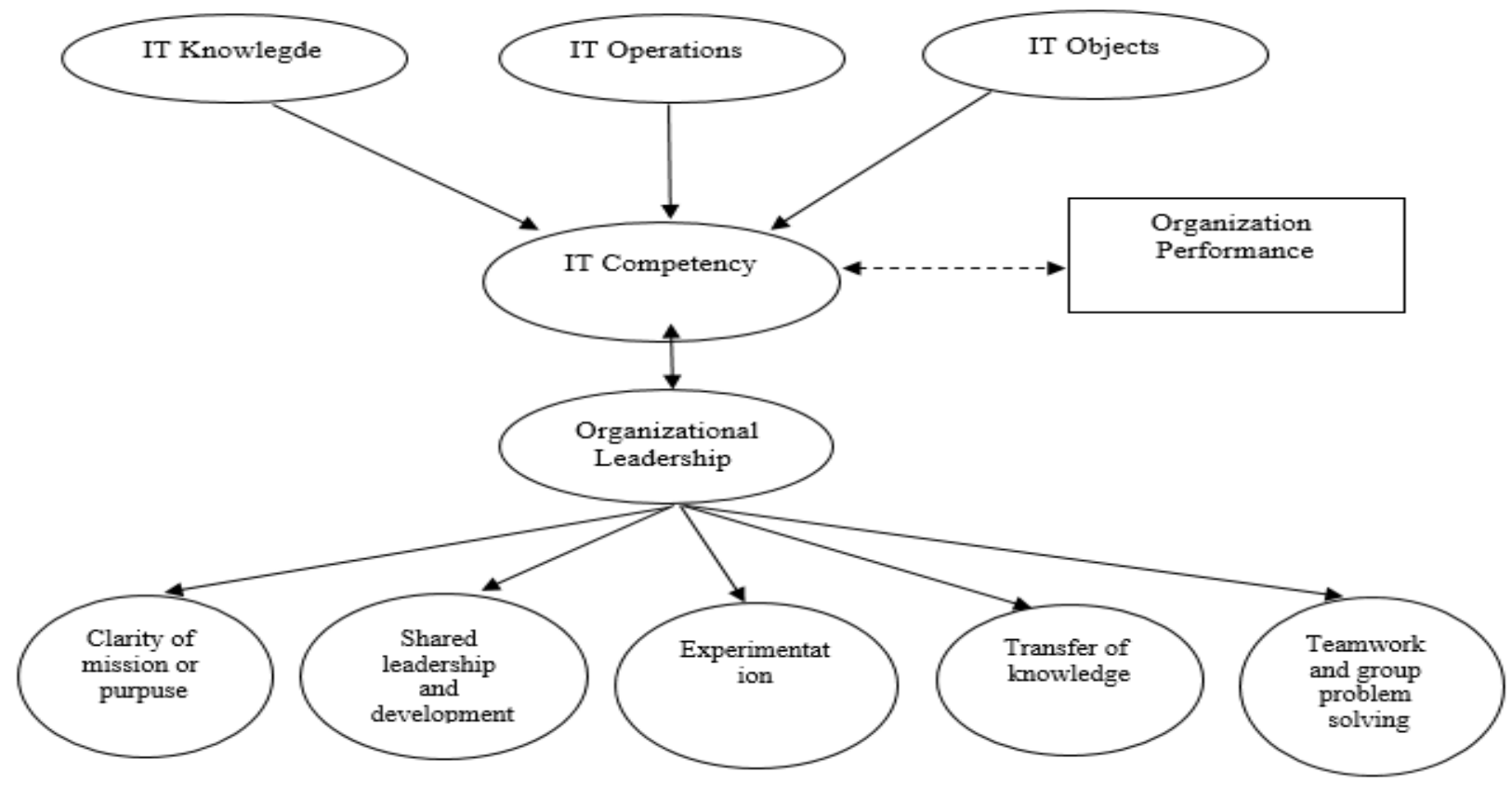

Figure 3. This explains the normative IT competency model in the organization for achieving the leadership role in the industries [12] 


\section{What benefits does information technology provide in a normal organization? \\ * Flow of information \\ * Decision support \\ * Workgroup support \\ * Executive support \\ * Data management \\ * Communication}

\subsection{Conclusion}

Information technologies and tools should be identified as instruments that can potentially move an organization into a more competitive position. Managers should ensure that all members of the organization understand and share in their understanding of their mission in order to achieve the leadership and that they all participate in helping the organization fulfill that purpose as this encourages people to think outside their 'silo.' Also, providing a safe space for people to experiment and try new ideas is critical for management when the correct answer is not already known. Finally, managers should encourage and facilitate knowledge sharing between members as it affords perspectives that exceed the sum of their individual outlooks [9]. The growing dependence on the information technology deeply influence the institutes, either due to its structure, form or because it offers the planned possibilities range just to progress the organization's sustained performance and to develop the informational technology's application as well. Together, managers that support these recommendations would situate their organization well for high-performing learning organizations necessary to make the best out of IT investments [13]. As market requires quality \& flexibility to cope up the demands and innovation is a key factor towards the achievement. The observation on technology is valid because the modern technological fluctuations moves in the shadow of modern organizations while leading role through the promotion of innovation. Research into the relationships between IT and organizational leadership has shown that simplistic models of the organization do not easily capture real-world dynamics of the use of IT in practice over time. This research also provides managers insight into how to achieve greater return and lead on investment in IT infrastructure, especially in the face of ever greater reliance on data-based technologies, through the support of organizational learning perspectives. Technology may be viewed as a simple tool. However, technology is also more. It embodies our own values and decisions which then provide enhanced leverage to enact those values making technology an extension of ourselves. Researchers and practitioners alike should work towards building a comprehensive understanding that reflects these broad interdisciplinary issues. By crossing the traditional boundaries of operational experience and the siloed perspectives of organizational research specialties, a unified body of knowledge on the consequences of technology [13-16] in the organization may be further illuminated aiding organizations well into the future. I think this is why many modern organizations are having such a difficult time adopting new technologies such as big data and analytics. These technologies are offering new possibilities for organizations that they have never foreseen.

\section{Reference}

[1] H. Li et al, "Influence of Transformational Leadership on Employees' Innovative Work Behavior in Sustainable Organizations: Test of Mediation and Moderation Processes," Sustainability, vol. 11, (6), pp. 1594, 2019.

[2] E. Hormiga et al, "The influence of entrepreneurial orientation on the performance of academic research groups: the mediating role of knowledge sharing," The Journal of Technology Transfer, vol. 42, (1), pp. 10-32, 2017. 
[3] M. Dodgson., D. M. Gann., \& N. Phillips. Organizational leadership and the technology of foolishness: The case of virtual worlds at IBM. Organization science, 24(5), 1358-1376,2013.

[4] A. De Geus. Planning as leadership. HARVARD BUSINESS REVIEW, 66(2), 70-74,1988.

[5] M. Ali and L. Miller, "ERP system implementation in large enterprises - a systematic literature review," Journal of Enterprise Information Management, vol. 30, (4), pp. 666-692, 2017.

[6] H.C. Huang. Technological innovation capability creation potential of open innovation: a cross-level analysis in the biotechnology industry. Technology Analysis \& Strategic Management, 23(1), 4963,2011.

[7] G. C. Kane., \& M. Alavi. Information technology and organizational leadership: An investigation of exploration and exploitation processes. Organization Science, 18(5), 796-812, 2007.

[8] T. K. Lant., F. J. Milliken., \& B. Batra. The role of managerial learning and interpretation in strategic persistence and reorientation: An empirical exploration. Strategic Management Journal, 13(8), 585608,1992 .

[9] Z. Shao, Y. Feng and Q. Hu, "Impact of top management leadership styles on ERP assimilation and the role of organizational learning," Information \& Management, vol. 54, (7), pp. 902-919, 2017.

[10] W. J. Orlikowski., \& S. R. Barley. Technology and institutions: What can research on information technology and research on organizations learn from each other? MIS quarterly, 25(2), 145-165,2001.

[11] J. C. Real., A. Leal., \& J.L. Roldán. Information technology as a determinant of organizational leadership and technological distinctive competencies. Industrial Marketing Management, 35(4), 505521,2006 .

[12] M. J. Tippins., \& R. S. Sohi. IT competency and firm performance: is organizational learning a missing link? Strategic management journal, 24(8), 745-761,2003.

[13] S. Rashid, A. Ahmed, I. Al Barazanchi, and Z. A. Jaaz, "Clustering algorithms subjected to K-mean and gaussian mixture model on multidimensional data set," Period. Eng. Nat. Sci., vol. 7, no. 2, pp. 448-457, 2019.

[14] L. Vladareanu, R. Lile, M. Radulescu, D. Mitroi, and D. Marin, "Intelligent control interfaces developed on Versatile Portable Intelligent Platform in order to improving autonomous navigation robots' performances," vol. 7, no. 1, pp. 324-329, 2019.

[15] M. Mohammed Yassine El Ghoumari, Abderrahmane Daif, Reda Moulouki, Houda Jihal, "Architectural Design of Trust Based Recommendation System in Customer Relationship Management,” Period. Eng. Nat. Sci., vol. 6, no. 2, pp. 380-388, 2018.

[16] M. Mohammed Yassine El Ghoumari, Abderrahmane Daif, Reda Moulouki, Houda Jihal, "Architectural Design of Trust Based Recommendation System in Customer Relationship Management," Period. Eng. Nat. Sci., vol. 6, no. 2, pp. 380-388, 2018. 